\title{
Review Article \\ HSV-1 as a Model for Emerging Gene Delivery Vehicles
}

\author{
Filip Lim \\ Departamento de Biología Molecular, Universidad Autónoma de Madrid, Cantoblanco, 28049 Madrid, Spain \\ Correspondence should be addressed to Filip Lim; filip.lim@uam.es
}

Received 17 April 2013; Accepted 10 May 2013

Academic Editors: A. Cid-Arregui and H. E. Kaufman

Copyright ( 2013 Filip Lim. This is an open access article distributed under the Creative Commons Attribution License, which permits unrestricted use, distribution, and reproduction in any medium, provided the original work is properly cited.

\begin{abstract}
The majority of viral vectors currently used possess modest cargo capability (up to $40 \mathrm{~kb}$ ) being based on retroviruses, lentiviruses, adenoviruses, and adenoassociated viruses. These vectors have made the most rapid transition from laboratory to clinic because their small genomes have simplified their characterization and modification. However, there is now an increasing need both in research and therapy to complement this repertoire with larger capacity vectors able to deliver multiple transgenes or to encode complex regulatory regions, constructs which can easily span more than $100 \mathrm{~kb}$. Herpes Simplex Virus Type I (HSV-1) is a wellcharacterized human virus which is able to package about $150 \mathrm{~kb}$ of DNA, and several vector systems are currently in development for gene transfer applications, particularly in neurons where other systems have low efficiency. However, to reach the same level of versatility and ease of use as that of smaller genome viral vectors, simple systems for high-titer production must be developed. This paper reviews the major HSV-1 vector systems and analyses the common elements which may be most important to manipulate to achieve this goal.
\end{abstract}

\section{Introduction}

Although horizontal gene transfer has long been recognized as an important factor in microbial evolution (reviewed in [1-3]) it is only recently that it has been recognized as a widespread phenomenon also in multicellular eukaryotes [46]. Among the multitude of mechanisms which have been identified, viruses have played and continue to play one of the major roles in horizontal gene transfer, leading to the concept of evolutionary units not being only cellular genomes but rather the sum of these plus their associated viruses $[7,8]$. Many different classes of viruses appear to have been implicated in the lateral transfer of transposable elements during eukaryotic evolution $[4,6,9-11]$ and together with the fact that a large variety of virus types continue to infect our cells, it is clear that a myriad of molecular mechanisms exist for the genetic modification of mammalian tissues.

Taking example from the exquisite specificity and efficiency of viruses to change the phenotype of the cells which they infect, attempts to make gene transfer tools have relied heavily on viral vectors (reviewed in [12-16]). This field of "vectorology" has followed a synthetic biology approach, using both natural and engineered components to construct gene delivery vehicles tailored to specific research or therapeutic aims. Understandably, most eukaryotic viral vectors currently being used are those derived from viruses with small-to-moderate genomes (up to $40 \mathrm{~kb}$ ) such as retroviruses, lentiviruses, adenoviruses, and adenoassociated viruses. These vectors have made the most rapid technological advances especially in the clinic [17] because their small genomes have simplified their comprehension and manipulation. However, there is now increasingly a need both in research as well as therapy to complement this repertoire with larger capacity vectors able to deliver multiple transgenes or to encode genomic regulatory regions, constructs which can easily span more than $100 \mathrm{~kb}$.

The discovery of giant viruses with megabase-sized genomes (reviewed in [18]) points towards future vectors capable of transferring complete sets of genes from living organisms, or even complete chromosomes, to study cell engineering not just by one or two transgenes but by multiple genetic cascades. Other nonviral forms of gene transfer will surely join this arsenal of gene transfer tools as gene circuits of greater and greater complexity are investigated [15]. However, to learn how to design and construct such vastly complex systems biology tools, vectors of intermediate size are needed as models to develop the DNA engineering technology to install 
the first "operating systems" which can be upgraded easily during this development stage. While smaller vectors derived from AAV, retroviruses, lentiviruses, and adenoviruses have undergone impressive modifications to decrease toxicity, enhance transgene expression, and maximize virion production, due to their limited cargo capacity, they have been useful mainly as single gene vectors. By using space-saving strategies borrowed from different viral genomes, as many as five separate proteins have been expressed from a retroviral vector [19]. However, these are coexpressed as a single RNA transcript, and as with many other current "multigene" viral vectors, the main objective is usually to simultaneously express various proteins in a target cell, such as reprogramming factors for generating induced pluripotent cells [20]. Other applications such as the gene transfer of portable versions of tetracycline-responsive switches [21] involve more sophisticated control of transgene expression with at least two different kinetics of transcription (the tetracycline-responsive regulator and the target transgene). Adenovirus vectors have even been used for gene transfer of whole genomic loci [22], opening the way to analyse and test more complex gene regulation mechanisms such as tissue-specificity and physiological responses to environmental cues.

In addition to molecular cell biology research focused on understanding components found in natural genomes, synthetic biology has now emerged as an important discipline, with applications such as RNAi-based synthetic regulation, the realtime physiological studies in live mammals with optogenetic gene circuits, and novel mammalian sensors and actuators (reviewed in [23]). An accelerating number of such studies are increasing our understanding of the function of individual transgenes together with their regulatory elements, and attempts to organize this information in databases of biomolecular "parts lists" have already begun [24-27]. While much research and development remain to fully master the task of reliable and efficient transgene expression using the compact and streamlined vectors based on small viruses, there is now a growing need to explore larger platforms for assembling networks of genes, to better understand and manipulate interactions among their products and regulatory regions.

\section{Viral Vectors Derived from HSV-1}

Herpes Simplex Virus Type 1 (HSV-1) has a number of characteristics in its favour as a model vector for emerging applications involving multigene circuits and/or large complex regulatory regions. It is able to package more than $160 \mathrm{~kb}$ of DNA [28], and viral vectors derived from its double-stranded DNA genome have been used extensively in numerous research and therapy applications [29-49]. The larger cargo capacity derives from a more complex viral genome which has been studied extensively at the basic mechanistic level [50], with important contributions to molecular biology such as the analysis of VP16 as a model for combinatorial mechanisms in transcriptional regulation [51]. The ability of the virus to change between lytic and latent modes of infection is also a subject of intense interest in understanding genetic switches, gene regulatory networks, and cellular modulation of vector DNA [52]. Thus, continued study of the coordinated function of HSV-1 genes will be important in understanding genomes of growing complexity in which individual genes have been studied in detail. In this respect it is significant that complete genome sequencing has been carried out already on many different isolates of HSV-1 [53-57], and BAC clones of some of the most widely used laboratory strains [58-63] can now be used to facilitate construction of vectors. The size of the genome $(152 \mathrm{~kb})$ and the number of genes (about 80 ) are significantly greater than those of AAV, retroviruses, lentiviruses and adenoviruses, but still within a manageable range, and current engineering of HSV-1 vectors is advancing more rapidly with the application of recently developed molecular tools such as ET cloning (recombineering) [64] and Cre-mediated BAC retrofitting [65].

Present use of gene transfer in humans is subject to two important restrictions: prohibition of germline modifications, due to ethical issues, and avoidance of replicationcompetent viral vectors, for biosafety reasons. Exceptions are replication-competent oncolytic viruses which are engineered to replicate vigorously in tumor tissues but not in normal cells. Although this topic will not be covered in this review it is worth noting that HSV-1 vectors have received particular attention for this application due to their differential lytic replication in fast-dividing epithelial cells compared to their latent state in nondividing neural cells. Since HSV1 is a neurotropic virus which efficiently infects many types of neurons in culture and in vivo, many of its applications in gene therapy have been in the nervous system. Despite encouraging progress in the search for pharmacological targets, most neurological diseases still remain incurable with few treatment options. Thus there is considerable interest in exploring more experimental therapeutic strategies such as gene therapy. In conventional small molecule pharmacology it is accepted that dosage, distribution, and kinetics play an all-important role in safety and efficacy. It thus follows that in the developing field of gene therapy it will not be sufficient to just express a gene product (all too often to as high a level as possible) but rather to try to achieve precise control over gene expression levels temporally and spatially. This highlights the advantage of the large coding capacity of HSV-1 vectors which enables the packaging of complete genes including natural genomic elements to maintain regulated physiological expression. The fact that regulatory sequences occupy more of the human genome than the genes themselves is an important reminder that alternative gene therapy approaches using the same gene can differ drastically in their efficacy in different tissues. Like conventional small molecule pharmacology, the success of any specific treatment in gene therapy will depend on many different aspects of each therapeutic agent such as its toxicity, biodistribution and kinetics. These properties have yet to be determined for different viral vectors for human applications and gene delivery to different tissues by different methods of administration in animal models will need to be explored to translate this to clinical trials. This topic is far too large to cover in this review which will focus on the vector platform rather than the transgenes or the delivery method. 


\section{Biology of HSV-1}

HSV-1 is a human pathogen with two replication modes based on its interaction with different cell types in the infected host. Initial attachment of the enveloped virion to the cell membrane is mediated by nonspecific interactions between viral envelope glycoproteins $\mathrm{B}$ or $\mathrm{C}$ ( $\mathrm{gB}$ or $\mathrm{gC}$ ) or both and glycosaminoglycan chains of proteoglycans on the cell surface (reviewed in [66, 67]). Penetration requires the specific interaction of $\mathrm{gD}$ with a cell entry receptor, two of which have been identified as Herpesvirus Entry Mediator (HVEM), also known as Tumor Necrosis Factor Receptor Superfamily member 14 (TNFRSF14), and nectin-1, also known as Poliovirus Receptor-related protein 1 (PVRL1) [67]. Either of these is sufficient for specific interaction with $\mathrm{gD}$ and subsequent triggering of membrane fusion, a process which involves $\mathrm{gB}, \mathrm{gH}$ and $\mathrm{gL}$ [66]. After initial infection and lytic replication, generally in oral or genital epithelial cells, the virus enters sensory neurons that innervate the infected epithelia. The viral capsids travel by microtubuledependent retrograde transport along the axons to the nuclei of the neurons, into which viral DNA is released through a capsid penton via nuclear pores. Lifelong latent infection of HSV-1 can be established in sensory ganglia, a state in which lytic genes are silenced and only the latency-associated (LAT) gene is transcribed into noncoding RNA [68]. This absence of viral protein expression in the latent state permits evasion of the immune system and ensures persistence of the virus within the host. Periodically, environmental cues such as ultraviolet radiation or stress provoke reactivation from latency, leading to the return of the virus to epithelial cells, where it can produce secondary infections resulting in mild illness symptoms, such as cold sores which normally disappear after immune responses in healthy individuals.

In lytic growth, the 80 odd genes are expressed in a well-ordered and tightly controlled cascade in which 3 classes of genes can be discerned: the immediate (IE) or $\alpha$ genes, the early (E) or $\beta$ genes, and the late (L) or $\gamma$ genes [69]. Efficient expression of the five IE genes does not require viral protein synthesis $[70,71]$ but is dependent on transactivation by VP16 (also known as Vmw65 or $\alpha$ TIF) $[72,73]$, a component of the viral tegument which interacts with the cellular proteins Oct 1 and Host Cell Factor (HCF) to bind to a consensus TAATGARAT sequence in IE gene promoters $[51,72,73]$. Another tegument protein, virion host shut-off (Vhs), shuts down host cell protein synthesis by degrading cellular mRNA [74]. One of the IE gene products, Infected Cell Polypeptide 47 (ICP47), has a role in immune evasion [75] while the activity of the other four (ICP0, ICP27, ICP4, and ICP22) stimulate the expression of the early (E) genes to the level required for the replication of viral DNA $[33,34]$. Finally, the late (L) genes are expressed, which mainly encode structural proteins enabling virion assembly. This precisely timed cascade of viral gene expression results in the production and release of infectious HSV-1 virus particles and the eventual death of the cell.

The HSV-1 genome can persist as an episome in sensory neurons where it may establish latency (reviewed in [7679]), a state in which neither viral proteins nor particles are detectable. In animal models, during the first few days after infection, it is possible to detect IE promoter-driven gene expression within sensory neurons which innervate the site of inoculation [80]. After this time, however, all lytic cycle promoters become transcriptionally repressed [81] and the only viral genes that are transcribed are the latencyassociated transcripts (LATs), whose functions have yet to be fully elucidated (reviewed in [82]). Studies indicate that these nonprotein coding LATs are involved in regulating the assembly of heterochromatin at lytic gene promoters, thus inducing transcriptional silencing $[36,37]$, possibly by acting as microRNAs which reduce expression of ICP0 and ICP4 [83]. Another LAT-derived microRNA has been described to confer resistance to apoptosis by modulating transforming growth factor- (TGF-) beta signaling [84]. Reactivation of HSV-1 lytic growth from the latent state appears to be a consequence of alterations in virus-host interactions but this is perhaps one of the least understood aspects of this virus.

\section{Recombinant HSV-1 Genomic Vectors: Transgenes Inserted in cis with Viral Genomes}

Perhaps the most obvious way to construct an HSV-1 vector is to insert transgenes directly within the viral genome so that they are copackaged into the viral particle along with the HSV-1 DNA. The key issue in this type of vector is the cytotoxicity due to the viral part of the infecting recombinant genome.

Deletion of any one of the approximately 40 essential viral genes (reviewed in [85]) is sufficient to create a replicationincompetent mutant, which can be grown on a complementing cell line which provides the missing gene product in trans. However, in spite of being unable to replicate, considerable expression of many other viral gene products still results in high cytotoxicity after infection with such modified genomes.

4.1. Multiple IE Gene Deletion Mutants. Since HSV-1 gene expression is tightly controlled in a cascade hierarchy, targetting of the five IE genes would seem an obvious strategy for overall inactivation of the virus. Mutants deleted in either of the two essential IE genes, ICP4 [86] or ICP27 [87], or simultaneously in both genes [88] still remain cytotoxic because of residual expression of the other IE genes $[89,90]$. Several mutant viruses inactivated for additional genes exhibit very low levels of cytotoxicity and form the basis of current state-of-the-art recombinant HSV-1 genomic vectors. Mutant viruses simultaneously deleted for ICP4, ICP27, and ICP22 provoke negligible cytopathic effects but infection of Vero cells leads to inhibition of DNA synthesis and cellular replication [91]. Other studies of similar mutants indicated that this effect is transient in dividing cells and that these mutants are nontoxic in neurons [92]. In recent clinical trials the safety of a mutant HSV-1 vector inactivated in ICP4, ICP27, ICP22, and ICP47 was confirmed for gene delivery into the dorsal root ganglia by intradermal injection $[93,94]$. 
Of the five IE proteins, ICP4, ICP27, and ICP0 have the most profound effects on the control of the rest of the HSV1 genome. Mutants deleted for all three of these IE genes show almost no cytotoxicity and permit the survival of a large percentage of Vero cells even after infection at high MOI [95] and when all five IE genes are deleted no detectable cytotoxicity is observed even when cells are infected at MOIs of up to 30 [96]. The only drawback with this approach is the difficulty in obtaining cell lines that simultaneously express multiple IE genes to provide full and consistent complementation: to date no truly stable cell line expressing all of the IE genes has been generated.

4.2. Mutants with Inactivated VP16. An alternative strategy to achieve nontoxic HSV-1 mutants without the need for complementing cell lines expressing troublesome IE proteins was illustrated by the construction of a virus with conditional mutations in the genes encoding ICP4, ICP0 as well as VP16, the viral tegument protein which enters the nucleus during infection and transactivates the IE gene promoters. Together with a temperature-sensitive mutation in ICP4 and a host range mutation of the ICP0 promoter, an insertion was introduced into the VP16 coding region which abolished its IE gene transactivation function. The resulting mutant virus underwent lytic replication to high titers in permissive conditions but infection of nonpermissive cells at a MOI of 5 resulted in no detectable cytopathology and the persistence of the viral genome within cells [97].

These results indicate that an alternative approach to eliminating the expression of all of the IE genes is to manipulate the gene encoding VP16. However, since VP16 is an essential structural component of the virion [98] deletion of its gene does not guarantee the elimination of its effects. This is because VP16 provided in trans in a complementing cell line (in order to grow VP16 deletion mutants) would be packaged into virions and carried over to target cells, where it would transactivate the IE gene promoters. This obstacle has been overcome by the discovery that the IE gene transactivation and virion assembly functions of VP16 are structurally separated in distinct domains [99]. Thus, as seen for the triple conditional HSV-1 mutant described above, mutations can be engineered into the VP16 gene to disable the IE gene transactivation function, while leaving intact the essential structural property enabling virion assembly $[100,101]$. Initially, propagation of mutants with such VP16 disabling mutations was complemented by growth on cells supplemented with hydroxymethyl bisacetamide (HMBA), a compound that exhibits stimulatory activity of HSV-1 immediate-early gene expression [102], but a more efficient system has been developed using cell lines expressing the equine herpesvirus homolog of VP16, following the discovery that this protein is not packaged into HSV-1 virions but can transactivate HSV-1 IE genes [103]. In particular, such cell lines support the high titer propagation of HSV-1 recombinant vectors in which a VP16 mutation has been combined with deletion of the ICP 4 and ICP27 genes. In nonpermissive cells, these mutants do not express significant amounts of any of the IE proteins, including ICP0, ICP22, and ICP47 although their genes have not been specifically deleted [104]. This system allows high titer production of nontoxic HSV-1 recombinant genomic vectors.

\section{Amplicon Vectors: Transgenes in Plasmids Packaged in Trans by Viral Genes}

HSV-1 amplicons [105] represent a different type of vector from the recombinant mutant viruses discussed above in that transgenes are inserted into plasmids containing an HSV-1 packaging signal consisting of a terminal a sequence and an HSV-1 origin of replication [106, 107]. This "gutless" genome (i.e., stripped of viral genes) can then be packaged into virions by introduction into packaging cells expressing all of the necessary HSV-1 proteins required to produce viral particles. Since packaging requires DNA molecules approximating the HSV-1 genome length, concatemers of the amplicon plasmid synthesized via rolling circle replication by the viral polymerase are cleaved in close to genome size units, which are then incorporated into virions. Although the effect of amplicon vector genome size on packaging efficiency has only been studied using smaller plasmids [108], indirect data suggest that as much as $160 \mathrm{~kb}$ may be carried within HSV-1 particles [28] and smaller constructs are packaged as multimers with a sum length closest to the full capsid capacity (reviewed in [105]). The exciting implications of this have already been illustrated by novel amplicon vectors carrying (1) whole genomic loci which retain their normal regulation by metabolite ligands when introduced into cultured fibroblasts [109] or stable longterm expression at physiological levels in the adult mammalian brain [110]; (2) multiple genetic elements including a double tetracycline-responsive system (both activator and silencer), two fluorescent protein reporters, a positron emission tomography (PET) marker gene and chromatin isolating elements [111]; (3) heterologous elements from AAV [112], EBV [113], cellular scaffold/matrix attachment regions (S/MARs) [114] and human alphoid DNA sequences [115] to confer new modes of vector maintenance in target cells (reviewed in [116]); (4) whole packaging systems for other viral vectors, opening up the possibility of viral "launchers" which after infecting a primary target cell are able fire off smaller vectors to extend gene delivery to secondary target cells [117-119].

Amplicon vectors have had a special niche in gene transfer for research applications because of their easy construction as simple plasmids. However, their production is more complex than that of recombinant genomic vectors since to date no stable cell line has been generated which can express all of the viral proteins necessary for HSV-1 vector packaging. Instead, these are currently introduced into packaging cells transiently (reviewed in [32]) either by infection with replication-defective HSV-1 mutants (helper viruses), or by transfection with replication-competent but packaging-defective HSV-1 genomes (cloned as plasmids).

5.1. Replication-Defective Helper Viruses. If, together with the amplicon plasmid, the viral genes are introduced into the 
packaging cell by infection with a helper virus then the resulting virions will be a mixture of those which have packaged the amplicon plasmids as well as those which contain helper genomes. The key issue in this system is the cytotoxicity due to the helper virus. Replication-incompetent helper viruses are used so that the final mixture of packaged amplicons and helper will not lyse target cells, but as discussed above for recombinant genomic vectors, even replication-incompetent HSV-1 mutants are still cytotoxic. It might appear that the best helper viruses to use would be those with simultaneous deletions in multiple IE genes and which exhibit the least cytotoxicity. However, since these mutants are difficult to grow to high titers, most routine amplicon production for research has only been carried out using helper viruses with single IE gene deletions $[120,121]$. Some data from studies comparing different replication-incompetent HSV-1 mutants indicated that the titer of amplicon vectors as well as their ratio with respect to helper virus decreases when more disabled helper viruses are used for packaging [121] but this issue has not been investigated in detail. The amplicon/helper ratio is also influenced by many other factors such as the size of the amplicon plasmid, the efficiency of cell transfection by the amplicon plasmid, and the MOI of helper virus [121, 122]. Since small amplicon plasmids fill viral particles as concatemers and contain multiple replication origins, their propagation is favoured compared to that of the helper virus genome. The observed cytotoxicity of such helper viruspackaged amplicon preparations in neuroscience research is often much lower than that portrayed for pure stocks of the helper virus for different reasons: first, since the majority of the virions are vector particles, the effective MOI of the helper virus is very low, whereas cytotoxicity assays of HSV1 mutants are usually carried out at high MOI; additionally, the HSV-1 genome is less cytotoxic in postmitotic neuronal tissue in vivo than in cultured neurons or epithelial cell lines which are often used for such analysis. Nevertheless, the variability in the ratio between vector and helper particles is difficult to control with helper-dependent amplicon systems and careful standardization of packaging procedures [123] is required to yield amplicon samples with consistently high ratios of vector to helper $[121,124]$ which have been suitable for high-efficiency neuronal gene transfer in proof of concept experiments in optogenetics [125-128] and gene therapy [129].

5.2. Conditional Packaging Helper Viruses. An improved method to improve significantly the vector to helper ratio was developed using Cre recombinase (supplied by a cell line expressing Cre) to excise a modified packaging signal flanked by LoxP sites in the helper virus [130]. In the latest version of this system the helper virus is deleted for the genes encoding ICP4 and the virulence factor ICP34.5, so that even the small amount of contaminating helper virus provokes little neurotoxicity [131]. This packaging system is capable of producing large quantities of almost nontoxic amplicon vector, albeit with small and variable amounts of contaminating helper virus. Although this is not a major obstacle for many research applications, the heterogeneity of the vector/helper mixture is a limitation in human gene therapy and in certain research applications with high sensitivity to cellular functions affected by viral pathways.

5.3. Helper-Free Amplicons. As an alternative to infection of the amplicon packaging cells with replication-defective helper viruses, the HSV-1 proteins necessary for virion production may be introduced by transfection of plasmids encoding the viral genome deleted for packaging signals. This was initially achieved by using a set of five overlapping cosmids, which by homologous recombination reconstitute wild-type HSV-1 virus genome in transfected cells [132]. The packaging signals were deleted from these cosmids, creating a system which can generate a modified HSV-1 genome expressing all viral functions but is unable to be packaged into virions [133]. Cotransfection of this modified cosmid set with amplicon plasmids resulted in packaged amplicon vector, containing minute contamination by viral genomes, which arose from recombination between the reconstituted modified HSV-1 genome and the amplicon plasmid [133]. Another difficulty with this system was the high frequency of mutation in bacteria of two of the cosmids which contain the HSV-1 repeat regions, giving rise to cosmid preparations unable to package amplicon vector. Thus, in the next step in this amplicon packaging approach, bacterial artificial chromosomes (BACs) were generated, containing the entire HSV-1 genome which had been deleted for packaging signals [58-60]. However, low frequency recombination between the amplicon and the BAC can still regenerate replicationcompetent HSV-1 in these systems. A sophisticated improved version was created a few years later in which a BAC containing the modified HSV-1 genome was further deleted for the essential gene encoding ICP27 and increased in size beyond the packaging limit of the virion by adding in extra copies of the ICP0 gene [28]. This system enables the production of entirely helper-free amplicon stocks and is ideal for research requiring high-efficiency neuronal gene transfer on a small scale. However, the amount of total amplicon vectors produced by this method is limited, as these stocks are produced by transfection and cannot be further amplified by simple growth cycles. Technically, this procedure also requires a certain amount of experience in preparing high quality HSV-1 BAC DNA for transfection, which is perhaps the largest obstacle limiting its widespread use.

\section{High-Titer Production of HSV-1 Vectors}

As can be seen from the above, various nonreplicative HSV-1 vector systems have been developed, each with certain characteristics of particular interest for different applications in research and/or therapy. These include recombinant genomic vectors with multiple IE gene deletions [34], VP16 disabled mutants [48], amplicons packaged with single IE gene deleted helpers [123], amplicons packaged with helpers containing Cre-excisable packaging signals (LaL), and BAC-packaged helper-free amplicons [28]. However, in spite of their attractive properties as gene transfer tools, HSV-1 vectors have not acquired the same widespread use as their smaller cousin 
vectors derived from $\mathrm{AAV}$, retroviruses, lentiviruses, and adenoviruses. Construction of recombinant genomic HSV-1 vectors was previously restricted to laboratories with virology tools and experience but has now become more amenable to other researchers with the availability of HSV-1 BAC clones [58-63] and methods for engineering these large constructs $[64,65]$. Some of these multiply deleted IE gene mutants can accommodate transgenes of $30 \mathrm{~kb}$ but the growth of such mutants becomes increasingly more difficult and less efficient as more viral DNA is deleted [134]. This problem is reminiscent of the decrease in amplicon packaging efficiency when helper viruses with larger deletions are used. In fact, rather than two separate types, recombinant genomic vectors and amplicons could be considered as the two extremes of HSV-1 vectors: deletion mutants progressively move the viral genes from being in cis to in trans with respect to the transgene. Vector production problems can thus be seen to appear when attempts are made to express the transacting viral genes from the cellular genome rather than from DNA delivered by an infecting virion. This section analyses some of the viral elements which may contribute most to alterations in titer when translocated from their natural configuration within the wild-type virus to a vector packaging system. The first three of these key players are the multifunctional protein products of IE genes: ICP27, known to inhibit cellular pre-mRNA splicing, recruit RNA polymerase II to viral replication sites, bind and export viral RNA to the cytoplasm and bind translation initiation factors; ICP4, a large phosphoprotein transactivator which can also act as a repressor of transcription; and ICP0, an E3 ubiquitin ligase RING finger domain protein known to have transcriptional activator activity and to disrupt nuclear structures such as promyelocytic (PML) bodies. For a detailed overview of the functions of these proteins the reader is referred to a recent review [135].

6.1. ICP27. The propagation of a virus deleted in a given gene requires that this missing gene product must be provided by a complementing cell line. This presents a potential problem for genes such as those of the IE class since the toxicity of their products means that cell lines directing their stable expression are difficult to generate. This obstacle can be overcome in cases such as ICP27 by using the native viral promoter to drive expression in the cell line, because such promoters are relatively inactive in the absence of viral infection and the low amounts of protein product produced by "leaky" expression under these conditions can be tolerated by the cell. Thus numerous cell lines stably transfected with DNA fragments containing the native ICP27 gene and promoter have been isolated $[87,88,103,136-138]$ and growth of ICP27 deletion mutants on many of these yields titers close to those of wild-type virus. Nevertheless in the context of a ICP27-deleted genomes containing further deletions, there is evidence that ICP27 complementation originating from the cell line does not mirror completely the function of viral-borne ICP27: (a) amplicon packaging by an HSV-1 BAC deleted for ICP27 is not efficient when carried out in an ICP27 complementing cell line; the ICP27 protein must also be supplied in trans by cotransfection with a ICP27expressing plasmid [28]; interaction was observed between ICP27 and ICP4 in stably transfected double-complementing cell lines [88], indicating that the presence of other viral genes in cis can influence the activity of the ICP27 gene.

6.2. ICP4. ICP4 deletion mutants can also be grown easily on complementing cell lines but virus yield is reduced compared to wild-type virus [139]. Cell lines stably transfected with the native ICP4 gene and promoter vary substantially in their efficiency to complement ICP4-defective viruses. One contributing factor for this is the high cytotoxicity of ICP4 which makes even low-level expression incompatible with cell viability. Stable cell lines which express sufficient ICP4 to permit efficient propagation of ICP4 deletion mutants do not express detectable levels of ICP4 in the absence of viral infection [140], a requirement which probably selects for stable transfectants containing the ICP4 transgene integrated into the cellular genome in such a way as to favour silencing. Thus clones must be selected in which this silencing can be reversed by viral infection to enable high ICP4 expression, and this may vary in efficiency according to the integration site as well as the ICP 4 transgene copy number. The variability of cellularly expressed ICP4 to complement is even more marked when combined with ICP27 expression to generate permissive cell llines to grow ICP4/ICP27 double deletion mutants [88]. Studies in which the ICP4 promoter was substituted for the ICP0 promoter achieved faster kinetics of ICP4 expression in response to viral infection of the complementing cells, leading to higher viral titers and the conclusion that the timing and level of ICP4 protein is critical [134]. One might have expected that optimal kinetics could be controlled by using an artificial inducible promoter but attempts to do this using the well-known tetracyclineresponsive system have been unsuccessful, probably because HSV-1 infected cell proteins appear to interfere significantly with transgene regulation using this system [63, 141-143]. Other attempts to control ICP4 expression by using tissuespecific promoters $[144,145]$ have also had little success, again due to interference by viral proteins. Different studies indicate that ICP4 itself is a major culprit, and indeed, one of its attributed activities is its ability to influence transcription by forming complexes with TFIID and Mediator [146].

6.3. ICP0. Although ICP0 is not an essential protein in HSV1 and null mutants of its gene can grow in tissue culture, their growth at low MOIs is substantially attenuated [147151] and their reactivation from latent infections impaired [152]. Curiously, the growth defect of ICP0 deletion mutants can be compensated for by a cellular activity present in certain cell lines such as BHK [97] or U2OS [153] although this complementation does not seem to be complete. Cell lines transfected with DNA fragments containing the ICP0 gene and promoter appear to be less stable than those transfected with other IE genes and like ICP4-containing cell lines, many stably-transfected clones must be screened to generate an efficient complementing cell line $[95,151]$. The most probable reason for this lies in the cytostatic properties 
of ICP0 [154]: the presence of this IE protein inhibits DNA synthesis and cell replication, and its expression is incompatible with cell survival $[90,95,155,156]$.

6.4. VP16. Since the activity of HSV-1 IE genes is greatly influenced by transactivation by the tegument protein VP16 $[72,73]$, when HSV-1 genomes are transfected as DNA, as in the BAC-mediated helper-free amplicon packaging procedure, lytic replication is substantially delayed due to altered IE gene expression kinetics. Indeed, preloading of the packaging cells by VP16 transfection increases amplicon vector titers, but curiously, only when vhs (another tegument protein) is coexpressed [157]. This suggests that inducible expression of VP16 in conjunction with vhs might be a possible strategy for obtaining high-titer packaging of different HSV-1 vectors. Given that one of the principal systems employs cell lines expressing the equine herpesvirus VP16 homolog to supply the IE transactivating function for packaging, it would be interesting to combine this approach to develop amplicon packaging cell lines.

6.5. Origins of Replication. In the wild-type HSV-1 genome there are three copies of replication origin (ori) sequences: two copies of ori $i_{S}$ and one copy of ori $\mathrm{L}_{\mathrm{L}}$. Although it appears that only one copy of an ori sequence is essential and an HSV-1 mutant deleted for both copies of ori S $_{S}$ is still viable, viral DNA replication is reduced [158]. Conversely, the fact that concatemers of amplicon plasmids have a replication advantage over helper viruses because of their multiple reiterations of HSV-1 suggests that increased ori copy number may augment vector propagation. This has not been investigated systematically but increasing vector replication with more copies of ori would probably be limited by the level of viral replication machinery available in the packaging cell. On the other hand, deletions of viral genes are complemented more efficiently if their gene products expressed from an ori $_{S}$-carrying plasmids than if they are expressed from a nonreplicating plasmid [159]. Thus a certain amount of feed-forward effect might be expected by the inclusion of ori sequences in cis with viral replication genes, making this a possible strategy for improving growth of difficult deletion mutants. Since ori $\mathrm{L}_{\mathrm{i}}$ is larger and more prone to recombination in bacteria [132], manipulations of ori S $_{S}$ are technically easier for vector engineering.

\section{Conclusions}

HSV-1 vectors provide an ideal synthetic biology platform for an emerging generation of experiments in research and application involving multicomponent genetic circuits and/or complex genomic regulatory regions. The intermediate genome size of HSV-1 $(150 \mathrm{~kb})$ in the world of viruses allows sufficient room to increase transgene payloads approximately one order of magnitude over many current viral vectors, but yet is still within a manageable level of complexity in terms of construction technology and modeling. The current bottleneck in HSV-1 vector technology is the availability of easy-to-use packaging systems capable of producing high-titer homogeneous vectors. Recombinant genomic vectors deleted for multiple genes to reduce toxicity or to accommodate larger transgenes become progressively harder to grow as more viral genes are deleted and have to be supplied by a complementing cell line. Amplicon packaging by helper viruses does not produce homogeneous vector preparations, so ideally, the helper virus used must be the least cytotoxic possible to interfere as little as possible with the amplicon vector. Since such helper viruses are those containing multiple deletions of IE genes, this method of preparing amplicon vectors faces the same obstacle as that of recombinant genomic vector production. On the other hand, amplicon packaging by cotransfection with HSV-1 BAC plasmids suffers from the limited titer produced by transfected cells, in part due to the severe alteration of cellular metabolism provoked by the transfection procedure. However, in spite of improved transfection technology with lower cytotoxicities, we have not observed a significant improvement in amplicon titers obtained using various such methods (unpublished results), implying that other important factors contribute to the difference in titer of amplicons obtained by transfection, compared to infection, of helper genomes. The answer perhaps lies in the generation of a stable helper-free amplicon packaging cell line which again comes back to a similar problem to generating complementing cell lines for multiply deleted HSV-1 mutants: how to obtain the conditional silencing of multiple genes from a lytic virus to allow them to be hosted by a viable cell line. On the other hand this relocation of viral genes into the packaging cell must not disrupt the finely tuned genetic circuitry necessary for high-titer virion production upon induction. Meeting the challenge of this engineering problem gives another good reason why HSV-1 provides a good model system to develop new generation vectors: one might say that viral evolution has already solved this problem, and the best ideas may come from an understanding of the molecular mechanisms involved in the lytic/latent switch of HSV-1.

\section{References}

[1] L. Boto, "Horizontal gene transfer in evolution: facts and challenges," Proceedings of the Royal Society B, vol. 277, no. 1683, pp. 819-827, 2010.

[2] R. Jain, M. C. Rivera, J. E. Moore, and J. A. Lake, "Horizontal gene transfer in microbial genome evolution," Theoretical Population Biology, vol. 61, no. 4, pp. 489-495, 2002.

[3] M. F. Polz, E. J. Alm, and W. P. Hanage, "Horizontal gene transfer and the evolution of bacterial and archaeal population structure," Trends in Genetics, vol. 29, no. 3, pp. 170-175, 2013.

[4] P. J. Keeling and J. D. Palmer, "Horizontal gene transfer in eukaryotic evolution," Nature Reviews Genetics, vol. 9, no. 8, pp. 605-618, 2008.

[5] S. Schaack, C. Gilbert, and C. Feschotte, "Promiscuous DNA: horizontal transfer of transposable elements and why it matters for eukaryotic evolution," Trends in Ecology and Evolution, vol. 25, no. 9, pp. 537-546, 2010.

[6] E. de la Casa-Esperon, "Horizontal transfer and the evolution of host-pathogen interactions," International Journal of Evolutionary Biology, vol. 2012, Article ID 679045, 9 pages, 2012. 
[7] D. Prangishvili, P. Forterre, and R. A. Garrett, "Viruses of the archaea: a unifying view," Nature Reviews Microbiology, vol. 4, no. 11, pp. 837-848, 2006.

[8] D. Raoult and P. Forterre, "Redefining viruses: lessons from mimivirus," Nature Reviews Microbiology, vol. 6, no. 4, pp. 315319, 2008 .

[9] M. G. Fischer and C. A. Suttle, "A virophage at the origin of large DNA transposons," Science, vol. 332, no. 6026, pp. 231-234, 2011.

[10] H. Liu, Y. Fu, D. Jiang et al., "Widespread horizontal gene transfer from double-stranded RNA viruses to eukaryotic nuclear genomes," Journal of Virology, vol. 84, no. 22, pp. 1187611887, 2010.

[11] H. Liu, Y. Fu, B. Li et al., "Widespread horizontal gene transfer from circular single-stranded DNA viruses to eukaryotic genomes," BMC Evolutionary Biology, vol. 11, article 276, 2011.

[12] D. Bouard, N. Alazard-Dany, and F. L. Cosset, "Viral vectors: from virology to transgene expression," The British Journal of Pharmacology, vol. 157, no. 2, pp. 153-165, 2009.

[13] M. A. Kay, J. C. Glorioso, and L. Naldini, "Viral vectors for gene therapy: the art of turning infectious agents into vehicles of therapeutics," Nature Medicine, vol. 7, no. 1, pp. 33-40, 2001.

[14] C. E. Thomas, A. Ehrhardt, and M. A. Kay, "Progress and problems with the use of viral vectors for gene therapy," Nature Reviews Genetics, vol. 4, no. 5, pp. 346-358, 2003.

[15] L. Vannucci, M. Lai, F. Chiuppesi, L. Ceccherini-Nelli, and M. Pistello, "Viral vectors: a look back and ahead on gene transfer technology," New Microbiologica, vol. 36, no. 1, pp. 1-22, 2013.

[16] J. N. Warnock, C. Daigre, and M. Al-Rubeai, "Introduction to viral vectors," Methods in Molecular Biology, vol. 737, pp. 1-25, 2011.

[17] S. L. Ginn, I. E. Alexander, M. L. Edelstein, M. R. Abedi, and J. Wixon, "Gene therapy clinical trials worldwide to 2012-an update," Journal of Gene Medicine, vol. 15, no. 2, pp. 65-77, 2013.

[18] J. M. Claverie and C. Abergel, "Open questions about giant viruses," Advances in Virus Research, vol. 85, pp. 25-56, 2013.

[19] P. de Felipe and M. Izquierdo, "Construction and characterization of pentacistronic retrovirus vectors," Journal of General Virology, vol. 84, part 5, pp. 1281-1285, 2003.

[20] B. W. Carey, S. Markoulaki, J. Hanna et al., "Reprogramming of murine and human somatic cells using a single polycistronic vector," Proceedings of the National Academy of Sciences of the United States of America, vol. 106, no. 1, pp. 157-162, 2009.

[21] J. Szulc, M. Wiznerowicz, M. O. Sauvain, D. Trono, and P. Aebischer, "A versatile tool for conditional gene expression and knockdown," Nature Methods, vol. 3, no. 2, pp. 109-116, 2006.

[22] G. Schiedner, N. Mortal, R. J. Parks et al., "Genomic DNA transfer with a high-capacity adenovirus vector results in improved in vivo gene expression and decreased toxicity," Nature Genetics, vol. 18, no. 2, pp. 180-183, 1998.

[23] A. L. Slusarczyk, A. Lin, and R. Weiss, "Foundations for the design and implementation of synthetic genetic circuits," Nature Reviews Genetics, vol. 13, no. 6, pp. 406-420, 2012.

[24] A. C. Forster and G. M. Church, "Towards synthesis of a minimal cell," Molecular systems biology, vol. 2, p. 45, 2006.

[25] C. J. A. Sigrist, L. Cerutti, E. de Castro et al., "PROSITE, a protein domain database for functional characterization and annotation," Nucleic Acids Research, vol. 38, no. 1, pp. D161D166, 2009.

[26] C. D. Smolke, "Building outside of the box: IGEM and the BioBricks foundation," Nature Biotechnology, vol. 27, no. 12, pp. 1099-1102, 2009.
[27] J. Wang, J. Zhuang, S. Iyer et al., "Factorbook.org: a Wikibased database for transcription factor-binding data generated by the ENCODE consortium," Nucleic Acids Research, vol. 41, pp. D171-D176, 2013.

[28] Y. Saeki, C. Fraefel, T. Ichikawa, X. O. Breakefield, and E. A. Chiocca, "Improved helper virus-free packaging system for HSV amplicon vectors using an ICP27-deleted, oversized HSV1 DNA in a bacterial artificial chromosome," Molecular Therapy, vol. 3, no. 4, pp. 591-601, 2001.

[29] S. J. Advani, R. R. Weichselbaum, R. J. Whitley, and B. Roizman, "Friendly fire: redirecting herpes simplex virus-1 for therapeutic applications," Clinical Microbiology and Infection, vol. 8, no. 9, pp. 551-563, 2002.

[30] E. Berto, A. Bozac, and P. Marconi, "Development and application of replication-incompetent HSV-1-based vectors," Gene Therapy, vol. 12, supplement 1, pp. S98-S102, 2005.

[31] E. A. Burton, Q. Bai, W. F. Goins, and J. C. Glorioso, “Targeting gene expression using HSV vectors," Advanced Drug Delivery Reviews, vol. 53, no. 2, pp. 155-170, 2001.

[32] A. L. Epstein, "HSV-1-derived amplicon vectors: recent technological improvements and remaining difficulties-a review," Memorias do Instituto Oswaldo Cruz, vol. 104, no. 3, pp. 399410, 2009.

[33] A. L. Epstein, P. Marconi, R. Argnani, and R. Manservigi, "HSV1-derived recombinant and amplicon vectors for gene transfer and gene therapy," Current Gene Therapy, vol. 5, no. 5, pp. 445458, 2005.

[34] D. J. Fink, N. A. DeLuca, M. Yamada, D. P. Wolfe, and J. C. Glorioso, "Design and application of HSV vectors for neuroprotection," Gene Therapy, vol. 7, no. 2, pp. 115-119, 2000.

[35] C. Fraefel, P. Marconi, and A. L. Epstein, "Herpes simplex virus type 1-derived recombinant and amplicon vectors," Methods in Molecular Biology, vol. 737, pp. 303-343, 2011.

[36] A. R. Frampton Jr., W. F. Goins, K. Nakano, E. A. Burton, and J. C. Glorioso, "HSV trafficking and development of gene therapy vectors with applications in the nervous system," Gene Therapy, vol. 12, no. 11, pp. 891-901, 2005.

[37] W. F. Goins, D. M. Krisky, J. B. Wechuck, D. Wolfe, S. Huang, and J. C. Glorioso, "Generation of replication-competent and -defective HSV vectors," Cold Spring Harbor Protocols, no. 5, Article ID pdb prot5615, 2011.

[38] P. Grandi, S. Wang, D. Schuback et al., "HSV-1 virions engineered for specific binding to cell surface receptors," Molecular Therapy, vol. 9, no. 3, pp. 419-427, 2004.

[39] O. C. Hibbitt and R. Wade-Martins, "Delivery of large genomic DNA inserts $>100 \mathrm{~kb}$ using HSV-1 amplicons," Current Gene Therapy, vol. 6, no. 3, pp. 325-336, 2006.

[40] C. Fraefel, "Gene delivery using helper virus-free HSV-1 amplicon vectors," Current Protocols in Neuroscience, vol. 4, p. 4.14, 2007.

[41] R. Manservigi, R. Argnani, and P. Marconi, "HSV recombinant vectors for gene therapy," Open Virology Journal, vol. 4, pp. 123156, 2010.

[42] P. Marconi, R. Manservigi, and A. L. Epstein, "HSV-1-derived helper-independent defective vectors, replicating vectors and amplicon vectors, for the treatment of brain diseases," Current Opinion in Drug Discovery and Development, vol. 13, no. 2, pp. 169-183, 2010.

[43] R. L. Neve, "Overview of gene delivery into cells using HSV-1based vectors," Current Protocols in Neuroscience, vol. 4, p. 4.12, 2012. 
[44] A. Oehmig, C. Fraefel, X. O. Breakefield, and M. Ackermann, "Herpes simplex virus type 1 amplicons and their hybrid virus partners, EBV, AAV, and retrovirus," Current Gene Therapy, vol. 4, no. 4, pp. 385-408, 2004.

[45] M. A. Spear, D. Schuback, K. Miyata et al., "HSV-1 amplicon peptide display vector," Journal of Virological Methods, vol. 107, no. 1, pp. 71-79, 2003.

[46] D. Wolfe, A. Niranjan, A. Trichel et al., "Safety and biodistribution studies of an HSV multigene vector following intracranial delivery to non-human primates," Gene Therapy, vol. 11, no. 23, pp. 1675-1684, 2004.

[47] A. M. Anesti, P. J. Peeters, I. Royaux, and R. S. Coffin, "Efficient delivery of RNA Interference to peripheral neurons in vivo using herpes simplex virus," Nucleic Acids Research, vol. 36, no. 14, article e86, 2008.

[48] C. E. Lilley and R. S. Coffin, "Construction of multiply disabled herpes simplex viral vectors for gene delivery to the nervous system," Methods in Molecular Medicine, vol. 76, pp. 33-49, 2003.

[49] M. C. P. Perez, S. P. Hunt, R. S. Coffin, and J. A. Palmer, "Comparative analysis of genomic HSV vectors for gene delivery to motor neurons following peripheral inoculation in vivo," Gene Therapy, vol. 11, no. 13, pp. 1023-1032, 2004.

[50] B. Roizman and B. Taddeo, "The strategy of herpes simplex virus replication and takeover of the host cell," in Human Herpesviruses: Biology, Therapy, and Immunoprophylaxis, 2007.

[51] J. Wysocka and W. Herr, "The herpes simplex virus VP16induced complex: the makings of a regulatory switch," Trends in Biochemical Sciences, vol. 28, no. 6, pp. 294-304, 2003.

[52] B. Roizman, "The checkpoints of viral gene expression in productive and latent infection: The role of the HDAC/CoREST/LSD1/REST repressor complex," Journal of Virology, vol. 85, no. 15, pp. 7474-7482, 2011.

[53] S. J. Macdonald, H. H. Mostafa, L. A. Morrison, and D. J. Davido, "Genome sequence of herpes simplex virus 1 strain KOS," Journal of Virology, vol. 86, no. 11, pp. 6371-6372, 2012.

[54] S. J. Macdonald, H. H. Mostafa, L. A. Morrison, and D. J. Davido, "Genome sequence of herpes simplex virus 1 strain McKrae," Journal of Virology, vol. 86, no. 17, pp. 9540-9541, 2012.

[55] D. J. McGeoch, M. A. Dalrymple, A. J. Davison et al., "The complete DNA sequence of the long unique region in the genome of herpes simplex virus type 1," Journal of General Virology, vol. 69, part 7, pp. 1531-1574, 1988.

[56] P. Norberg, S. Tyler, A. Severini, R. Whitley, J. Å. Liljeqvist, and T. Bergström, "A genome-wide comparative evolutionary analysis of herpes simplex virus type 1 and varicella zoster virus," PLoS ONE, vol. 6, no. 7, Article ID e22527, 2011.

[57] M. L. Szpara, L. Parsons, and L. W. Enquist, "Sequence variability in clinical and laboratory isolates of herpes simplex virus 1 reveals new mutations," Journal of Virology, vol. 84, no. 10, pp. 5303-5313, 2010.

[58] T. A. Stavropoulos and C. A. Strathdee, "An enhanced packaging system for helper-dependent herpes simplex virus vectors," Journal of Virology, vol. 72, no. 9, pp. 7137-7143, 1998.

[59] Y. Saeki, T. Ichikawa, A. Saeki et al., "Herpes simplex virus type 1 DNA amplified as bacterial artificial chromosome in Escherichia coli: rescue of replication-competent virus progeny and packaging of amplicon vectors," Human Gene Therapy, vol. 9, no. 18, pp. 2787-2794, 1998.

[60] B. C. Horsburgh, M. M. Hubinette, D. Qiang, M. L. E. MacDonald, and F. Tufaro, "Allele replacement: an application that permits rapid manipulation of herpes simplex virus type 1 genomes," Gene Therapy, vol. 6, no. 5, pp. 922-930, 1999.

[61] M. Tanaka, H. Kagawa, Y. Yamanashi, T. Sata, and Y. Kawaguchi, "Construction of an excisable bacterial artificial chromosome containing a full-length infectious clone of herpes simplex virus type 1: viruses reconstituted from the clone exhibit wild-type properties in vitro and in vivo," Journal of Virology, vol. 77, no. 2, pp. 1382-1391, 2003.

[62] W. W. Gierasch, D. L. Zimmerman, S. L. Ward, T. K. VanHeyningen, J. D. Romine, and D. A. Leib, "Construction and characterization of bacterial artificial chromosomes containing HSV-1 strains 17 and KOS," Journal of Virological Methods, vol. 135, no. 2, pp. 197-206, 2006.

[63] C. W. Knopf, O. Zavidij, I. Rezuchova, and J. Rajčáni, "Evaluation of the T-RExU transcription switch for conditional expression and regulation of HSV-1 vectors," Virus Genes, vol. 36, no. 1, pp. 55-66, 2008.

[64] Y. Zhang, F. Buchholz, J. P. P. Muyrers, and A. Francis Stewart, "A new logic for DNA engineering using recombination in Escherichia coli," Nature Genetics, vol. 20, no. 2, pp. 123-128, 1998.

[65] S. Y. Kim, S. K. Horrigan, J. L. Altenhofen, Z. H. Arbieva, R. Hoffman, and C. A. Westbrook, "Modification of bacterial artificial chromosome clones using Cre recombinase introduction of selectable markers for expression in eukaryotic cells," Genome Research, vol. 8, no. 4, pp. 404-412, 1998.

[66] G. Campadelli-Fiume and L. Menotti, "Entry of alphaherpesviruses into the cell," in Human Herpesviruses: Biology, Therapy, and Immunoprophylaxis, 2007.

[67] J. M. Taylor, E. Lin, N. Susmarski et al., "Alternative entry receptors for herpes simplex virus and their roles in disease," Cell Host and Microbe, vol. 2, no. 1, pp. 19-28, 2007.

[68] J. G. Stevens, E. K. Wagner, and G. B. Devi-Rao, "RNA complementary to a herpesvirus $\alpha$ gene mRNA is prominent in latently infected neurons," Science, vol. 235, no. 4792, pp. 10561059, 1987.

[69] R. W. Honess and B. Roizman, "Regulation of herpesvirus macromolecular synthesis. I. Cascade regulation of the synthesis of three groups of viral proteins," Journal of Virology, vol. 14, no. 1, pp. 8-19, 1974.

[70] K. P. Anderson, R. H. Costa, L. E. Holland, and E. K. Wagner, "Characterization of herpes simplex virus type 1 RNA present in the absence of de novo protein synthesis," Journal of Virology, vol. 34, no. 1, pp. 9-27, 1980.

[71] R. J. Watson and J. B. Clements, "A herpes simplex virus type 1 function continuously required for early and late virus RNA synthesis," Nature, vol. 285, no. 5763, pp. 329-330, 1980.

[72] D. F. Gaffney, J. Mclauchlan, J. L. Whitton, and J. B. Clements, "A modular system for the assay of transcription regulatory signals: the sequence TAATGARAT is required for herpes simplex virus immediate early gene activation," Nucleic Acids Research, vol. 13, no. 21, pp. 7847-7863, 1985.

[73] S. Mackem and B. Roizman, "Differentiation between alpha promoter and regulator regions of herpes simplex virus 1 : the functional domains and sequence of a movable alpha regulator," Proceedings of the National Academy of Sciences of the United States of America, vol. 79, no. 16, pp. 4917-4921, 1982.

[74] A. A. Oroskar and G. S. Read, "Control of mRNA stability by the virion host shutoff function of herpes simplex virus," Journal of Virology, vol. 63, no. 5, pp. 1897-1906, 1989. 
[75] A. Hill, P. Jugovic, I. York et al., "Herpes simplex virus turns off the TAP to evade host immunity," Nature, vol. 375, no. 6530, pp. 411-415, 1995.

[76] J. G. Stevens, "Human herpesviruses: a consideration of the latent state," Microbiological Reviews, vol. 53, no. 3, pp. 318-332, 1989.

[77] I. Steiner and P. G. E. Kennedy, "Molecular biology of herpes simplex virus type 1 latency in the nervous system," Molecular Neurobiology, vol. 7, no. 2, pp. 137-159, 1993.

[78] C. Jones, "Herpes simplex virus type 1 and bovine herpesvirus 1 latency," Clinical Microbiology Reviews, vol. 16, no. 1, pp. 79-95, 2003.

[79] G. C. Perng and C. Jones, "Towards an understanding of the herpes simplex virus type 1 latency-reactivation cycle," Interdisciplinary Perspectives on Infectious Diseases, vol. 2010, Article ID 262415, 18 pages, 2010.

[80] R. H. Lachmann, M. Sadarangani, H. R. Atkinson, and S. Efstathiou, "An analysis of herpes simplex virus gene expression during latency establishment and reactivation," Journal of General Virology, vol. 80, part 5, pp. 1271-1282, 1999.

[81] C. M. Preston, "Repression of viral transcription during herpes simplex virus latency," Journal of General Virology, vol. 81, part 1, pp. 1-19, 2000.

[82] J. R. Kent, W. Kang, C. G. Miller, and N. W. Fraser, "Herpes simplex virus latency-associated transcript gene function," Journal of NeuroVirology, vol. 9, no. 3, pp. 285-290, 2003.

[83] J. L. Umbach, M. F. Kramer, I. Jurak, H. W. Karnowski, D. M. Coen, and B. R. Cullen, "MicroRNAs expressed by herpes simplex virus 1 during latent infection regulate viral mRNAs," Nature, vol. 454, no. 7205, pp. 780-783, 2008.

[84] A. Gupta, J. J. Gartner, P. Sethupathy, A. G. Hatzigeorgiou, and N. W. Fraser, "Anti-apoptotic function of a microRNA encoded by the HSV-1 latency-associated transcript," Nature, vol. 442, no. 7098, pp. 82-85, 2006.

[85] Y. Nishiyama, "Herpesvirus genes: molecular basis of viral replication and pathogenicity," Nagoya Journal of Medical Science, vol. 59, no. 3-4, pp. 107-119, 1996.

[86] N. A. DeLuca, A. M. McCarthy, and P. A. Schaffer, "Isolation and characterization of deletion mutants of herpes simplex virus type 1 in the gene encoding immediate-early regulatory protein ICP4," Journal of Virology, vol. 56, no. 2, pp. 558-570, 1985.

[87] A. M. McCarthy, L. McMahan, and P. A. Schaffer, "Herpes simplex virus type 1 ICP27 deletion mutants exhibit altered patterns of transcription and are DNA deficient," Journal of Virology, vol. 63, no. 1, pp. 18-27, 1989.

[88] L. A. Samaniego, A. L. Webb, and N. A. DeLuca, "Functional interactions between herpes simplex virus immediate-early proteins during infection: gene expression as a consequence of ICP27 and different domains of ICP4," Journal of Virology, vol. 69, no. 9, pp. 5705-5715, 1995.

[89] P. A. Johnson, A. Miyanohara, F. Levine, T. Cahill, and T. Friedmann, "Cytotoxicity of a replication-defective mutant of herpes simplex virus type I," Journal of Virology, vol. 66, no. 5, pp. 2952-2965, 1992.

[90] P. A. Johnson, M. J. Wang, and T. Friedmann, "Improved cell survival by the reduction of immediate-early gene expression in replication-defective mutants of herpes simplex virus type 1 but not by mutation of the virion host shutoff function," Journal of Virology, vol. 68, no. 10, pp. 6347-6362, 1994.

[91] N. Wu, S. C. Watkins, P. A. Schaffer, and N. A. DeLuca, "Prolonged gene expression and cell survival after infection by a herpes simplex virus mutant defective in the immediate-early genes encoding ICP4, ICP27, and ICP22," Journal of Virology, vol. 70, no. 9, pp. 6358-6369, 1996.

[92] D. M. Krisky, D. Wolfe, W. F. Coins et al., "Deletion of multiple immediate-early genes from herpes simplex virus reduces cytotoxicity and permits long-term gene expression in neurons," Gene Therapy, vol. 5, no. 12, pp. 1593-1603, 1998.

[93] D. J. Fink, J. Wechuck, M. Mata et al., "Gene therapy for pain: results of a phase I clinical trial," Annals of Neurology, vol. 70, no. 2, pp. 207-212, 2011.

[94] D. J. Fink and D. Wolfe, "Gene therapy for pain: a perspective," Pain Management, vol. 1, no. 5, pp. 379-381, 2011.

[95] L. A. Samaniego, N. Wu, and N. A. DeLuca, "The herpes simplex virus immediate-early protein ICP0 affects transcription from the viral genome and infected-cell survival in the absence of ICP4 and ICP27," Journal of Virology, vol. 71, no. 6, pp. 46144625, 1997.

[96] L. A. Samaniego, L. Neiderhiser, and N. A. DeLuca, "Persistence and expression of the herpes simplex virus genome in the absence of immediate-early proteins," Journal of Virology, vol. 72, no. 4, pp. 3307-3320, 1998.

[97] C. M. Preston, R. Mabbs, and M. J. Nicholl, "Construction and characterization of herpex simplex virus type 1 mutants with conditional defects in immediate early gene expression," Virology, vol. 229, no. 1, pp. 228-239, 1997.

[98] W. Batterson and B. Roizman, "Characterization of the herpes simplex virion-associated factor responsible for the induction of $\alpha$ genes," Journal of Virology, vol. 46, no. 2, pp. 371-377, 1983.

[99] C. I. Ace, T. A. McKee, J. M. Ryan, J. M. Cameron, and C. M. Preston, "Construction and characterization of a herpes simplex virus type 1 mutant unable to transinduce immediate-early gene expression," Journal of Virology, vol. 63, no. 5, pp. 2260-2269, 1989.

[100] J. R. Smiley and J. Duncan, "Truncation of the C-terminal acidic transcriptional activation domain of herpes simplex virus VP16 produces a phenotype similar to that of the in 1814 linker insertion mutation," Journal of Virology, vol. 71, no. 8, pp. 61916193, 1997.

[101] I. Steiner, J. G. Spivack, S. L. Deshmane, C. I. Ace, C. M. Preston, and N. W. Fraser, "A herpes simplex virus type 1 mutant containing a nontransducing Vmw65 protein establishes latent infection in vivo in the absence of viral replication and reactivates efficiently from explanted trigeminal ganglia," Journal of Virology, vol. 64, no. 4, pp. 1630-1638, 1990.

[102] M. McFarlane, J. I. Daksis, and C. M. Preston, "Hexamethylene bisacetamide stimulates herpes simplex virus immediate early gene expression in the absence of trans-induction by Vmw65," Journal of General Virology, vol. 73, part 2, pp. 285-292, 1992.

[103] S. K. Thomas, C. E. Lilley, D. S. Latchman, and R. S. Coffin, "Equine herpesvirus 1 gene 12 can substitute for vmw65 in the growth of herpes simplex virus (HSV) type 1, allowing the generation of optimized cell lines for the propagation of HSV vectors with multiple immediate-early gene defects," Journal of Virology, vol. 73, no. 9, pp. 7399-7409, 1999.

[104] C. E. Lilley, F. Groutsi, Z. Han et al., "Multiple immediate-early gene-deficient herpes simplex virus vectors allowing efficient gene delivery to neurons in culture and widespread gene delivery to the central nervous system in vivo," Journal of Virology, vol. 75, no. 9, pp. 4343-4356, 2001.

[105] N. Frenkel, "The history of the HSV amplicon: from naturally occurring defective genomes to engineered amplicon vectors," Current Gene Therapy, vol. 6, no. 3, pp. 277-301, 2006. 
[106] R. R. Spaete and N. Frenkel, "The herpes simplex virus amplicon: a new eucaryotic defective-virus cloning-amplifying vector," Cell, vol. 30, no. 1, pp. 295-304, 1982.

[107] R. R. Spaete and N. Frenkel, "The herpes simplex virus amplicon: analyses of cis-acting replication functions," Proceedings of the National Academy of Sciences of the United States of America, vol. 82, no. 3, pp. 694-698, 1985.

[108] A. D. Kwong and N. Frenkel, "Herpes simplex virus amplicon: effect of size on replication of constructed defective genomes containing eucaryotic DNA sequences," Journal of Virology, vol. 51, no. 3, pp. 595-603, 1984.

[109] R. Wade-Martins, Y. Saeki, and E. A. Chiocca, "Infectious delivery of a 135-kb LDLR genomic locus leads to regulated complementation of low-density lipoprotein receptor deficiency in human cells," Molecular Therapy, vol. 7, no. 5, part 1, pp. 604612, 2003.

[110] A. Gimenez-Cassina, R. Wade-Martins, S. Gomez-Sebastian, J. C. Corona, F. Lim, and J. Diaz-Nido, "Infectious delivery and long-term persistence of transgene expression in the brain by a 135-kb iBAC-FXN genomic DNA expression vector," Gene Therapy, vol. 18, no. 10, pp. 1015-1019, 2011.

[111] A. Winkeler, M. Sena-Esteves, L. E. Paulis et al., "Switching on the lights for gene therapy," PloS ONE, vol. 2, no. 6, article e528, 2007.

[112] K. M. Johnston, D. Jacoby, P. A. Pechan et al., "HSV/AAV hybrid amplicon vectors extend transgene expression in human glioma cells," Human Gene Therapy, vol. 8, no. 3, pp. 359-370, 1997.

[113] S. Wang and J. M. Vos, "A hybrid herpesvirus infectious vector based on Epstein-Barr virus and herpes simplex virus type 1 for gene transfer into human cells in vitro and in vivo," Journal of Virology, vol. 70, no. 12, pp. 8422-8430, 1996.

[114] M. M. P. Lufino, R. Manservigi, and R. Wade-Martins, "An S/MAR-based infectious episomal genomic DNA expression vector provides long-term regulated functional complementation of LDLR deficiency," Nucleic Acids Research, vol. 35, no. 15, article e98, 2007.

[115] D. Moralli, K. M. Simpson, R. Wade-Martins, and Z. L. Monaco, "A novel human artificial chromosome gene expression system using herpes simplex virus type 1 vectors," EMBO Reports, vol. 7, no. 9, pp. 911-918, 2006.

[116] M. M. P. Lufino, P. A. H. Edser, and R. Wade-Martins, "Advances in high-capacity extrachromosomal vector technology: episomal maintenance, vector delivery, and transgene expression," Molecular Therapy, vol. 16, no. 9, pp. 1525-1538, 2008.

[117] N. Savard, F. L. Cosset, and A. L. Epstein, "Defective herpes simplex virus type 1 vectors harboring gag, pol, and env genes can be used to rescue defective retrovirus vectors," Journal of Virology, vol. 71, no. 5, pp. 4111-4117, 1997.

[118] P. de Felipe, M. Izquierdo, F. Wandosell, and F. Lim, "Integrating retroviral cassette extends gene delivery of HSV-1 expression vectors to dividing cells," BioTechniques, vol. 31, no. 2, pp. 394405, 2001.

[119] M. Sena-Esteves, Y. Saeki, S. M. Camp, E. A. Chiocca, and X. O. Breakefield, "Single-step conversion of cells to retrovirus vector producers with herpes simplex virus-Epstein-Barr virus hybrid amplicons," Journal of Virology, vol. 73, no. 12, pp. 10426-10439, 1999.

[120] A. I. Geller, K. Keyomarsi, J. Bryan, and A. B. Pardee, "An efficient deletion mutant packaging system for defective herpes simplex virus vectors: potential applications to human gene therapy and neuronal physiology," Proceedings of the National
Academy of Sciences of the United States of America, vol. 87, no. 22, pp. 8950-8954, 1990.

[121] F. Lim, D. Hartley, P. Starr et al., "Generation of high-titer defective HSV-1 vectors using an IE 2 deletion mutant and quantitative study of expression in cultured cortical cells," BioTechniques, vol. 20, no. 3, pp. 460-469, 1996.

[122] X. Wu, Y. Leduc, M. Cynader, and F. Tufaro, "Examination of conditions affecting the efficiency of HVS-1 amplicon packaging," Journal of Virological Methods, vol. 52, no. 1-2, pp. 219-229, 1995.

[123] R. L. Neve and F. Lim, "Generation of high-titer defective HSV-1 vectors," Current Protocols in Neuroscience, vol. 4, p. 4.13, 2013.

[124] F. Lim and R. L. Neve, "Generation of high-titer defective HSV-1 vectors," Current Protocols in Neuroscience, vol. 4, p. 4.13, 2001.

[125] D. Chaudhury, J. J. Walsh, A. K. Friedman et al., "Rapid regulation of depression-related behaviours by control of midbrain dopamine neurons," Nature, vol. 493, no. 7433, pp. 532-536.

[126] H. E. Covington III, M. K. Lobo, I. Maze et al., "Antidepressant effect of optogenetic stimulation of the medial prefrontal cortex," Journal of Neuroscience, vol. 30, no. 48, pp.16082-16090, 2010.

[127] S. Y. Kim, A. Adhikari, S. Y. Lee et al., "Diverging neural pathways assemble a behavioural state from separable features in anxiety," Nature, vol. 496, no. 7444, pp. 219-223.

[128] M. K. Lobo, H. E. Covington, D. Chaudhury et al., "Cell typespecific loss of BDNF signaling mimics optogenetic control of cocaine reward," Science, vol. 330, no. 6002, pp. 385-390, 2010.

[129] F. Lim, G. M. Palomo, C. Mauritz et al., "Functional recovery in a Friedreich's ataxia mouse model by frataxin gene transfer using an HSV-1 amplicon vector," Molecular Therapy, vol. 15, no. 6, pp. 1072-1078, 2007.

[130] C. Logvinoff and A. L. Epstein, "Genetic engineering of herpes simplex virus and vector genomes carrying loxP sites in cells expressing Cre recombinase," Virology, vol. 267, no. 1, pp. 102$110,2000$.

[131] C. Zaupa, V. Revol-Guyot, and A. L. Epstein, "Improved packaging system for generation of high-level noncytotoxic HSV1 amplicon vectors using Cre-loxP site-specific recombination to delete the packaging signals of defective helper genomes," Human Gene Therapy, vol. 14, no. 11, pp. 1049-1063, 2003.

[132] C. Cunningham and A. J. Davison, "A cosmid-based system for constructing mutants of herpes simplex virus type 1," Virology, vol. 197, no. 1, pp. 116-124, 1993.

[133] C. Fraefel, S. Song, F. Lim et al., "Helper virus-free transfer of herpes simplex virus type 1 plasmid vectors into neural cells," Journal of Virology, vol. 70, no. 10, pp. 7190-7197, 1996.

[134] K. G. Grant, D. M. Krisky, M. M. Ataai, and J. C. Glorioso, "Engineering cell lines for production of replication defective HSV-1 gene therapy vectors," Biotechnology and Bioengineering, vol. 102, no. 4, pp. 1087-1097, 2009.

[135] S. K. Weller, Ed., Alphaherpesviruses: Molecular Virology, Caister Academic Press, Norfolk, UK, 2011.

[136] M. K. Howard, T. Kershaw, B. Gibb et al., "High efficiency gene transfer to the central nervous system of rodents and primates using herpes virus vectors lacking functional ICP27 and ICP34.5," Gene Therapy, vol. 5, no. 8, pp. 1137-1147, 1998.

[137] W. R. Sacks, C. C. Greene, D. P. Aschman, and P. A. Schaffer, "Herpes simpex virus type $1 \mathrm{ICP} 27$ is an essential regulatory protein," Journal of Virology, vol. 55, no. 3, pp. 796-805, 1985.

[138] I. L. Smith, M. A. Hardwicke, and R. M. Sandri-Goldin, "Evidence that the herpes simplex virus immediate early protein 
ICP27 acts post-transcriptionally during infection to regulate gene expression," Virology, vol. 186, no. 1, pp. 74-86, 1992.

[139] N. A. Deluca and P. A. Schaffer, "Activities of herpes simplex virus type 1 (HSV-1) ICP4 genes specifying nonsense peptides," Nucleic Acids Research, vol. 15, no. 11, pp. 4491-4511, 1987.

[140] Y. H. Su, X. Zhang, X. Wang, N. W. Fraser, and T. M. Block, "Evidence that the immediate-early gene product ICP4 is necessary for the genome of the herpes simplex virus type 1 ICP4 deletion mutant strain d120 to circularize in infected cells," Journal of Virology, vol. 80, no. 23, pp. 11589-11597, 2006.

[141] K. H. Choi, K. H. Kim, and H. J. Kim, "Evaluation of tTAmediated gene activation system on human cytomegalovirus and herpes simplex virus type-1 infections," Archives of Pharmacal Research, vol. 23, no. 3, pp. 257-260, 2000.

[142] M. E. Fotaki, J. R. Pink, and J. Mous, “Tetracycline-responsive gene expression in mouse brain after amplicon-mediated gene transfer," Gene Therapy, vol. 4, no. 9, pp. 901-908, 1997.

[143] U. Herrlinger, P. A. Pechan, A. H. Jacobs et al., "HSV-1 infected cell proteins influence tetracycline-regulated transgene expression," Journal of Gene Medicine, vol. 2, no. 5, pp. 379-389, 2000.

[144] S. I. Miyatake, A. Iyer, R. L. Martuza, and S. D. Rabkin, "Transcriptional targeting of herpes simplex virus for cellspecific replication," Journal of Virology, vol. 71, no. 7, pp. 51245132, 1997.

[145] P. A. Pechan, M. Fotaki, R. L. Thompson et al., "A novel "piggyback" packaging system for herpes simplex virus amplicon vectors," Human Gene Therapy, vol. 7, no. 16, pp. 2003-2013, 1996.

[146] J. T. Lester and N. A. DeLuca, "Herpes simplex virus 1 ICP4 forms complexes with TFIID and mediator in virus-infected cells," Journal of Virology, vol. 85, no. 12, pp. 5733-5744, 2011.

[147] N. D. Stow and E. C. Stow, "Isolation and characterization of a herpes simplex virus type 1 mutant containing a deletion within the gene encoding the immediate early polypeptide Vmw110," Journal of General Virology, vol. 67, part 12, pp. 2571-2585, 1986.

[148] W. Cai, T. L. Astor, L. M. Liptak, C. Cho, D. M. Coen, and P. A. Schaffer, "The herpes simplex virus type 1 regulatory protein ICP0 enhances virus replication during acute infection and reactivation from latency," Journal of Virology, vol. 67, no. 12, pp. 7501-7512, 1993.

[149] W. P. Halford and P. A. Schaffer, "Optimized viral dose and transient immunosuppression enable herpes simplex virus ICP0null mutants to establish wild-type levels of latency in vivo," Journal of Virology, vol. 74, no. 13, pp. 5957-5967, 2000.

[150] D. A. Leib, D. M. Coen, C. L. Bogard et al., "Immediateearly regulatory gene mutants define different stages in the establishment and reactivation of herpes simplex virus latency," Journal of Virology, vol. 63, no. 2, pp. 759-768, 1989.

[151] W. R. Sacks and P. A. Schaffer, "Deletion mutants in the gene encoding the herpes simplex virus type 1 immediate-early protein ICP0 exhibit impaired growth in cell culture," Journal of Virology, vol. 61, no. 3, pp. 829-839, 1987.

[152] W. P. Halford and P. A. Schaffer, "ICP0 is required for efficient reactivation of herpes simplex virus type 1 from neuronal latency," Journal of Virology, vol. 75, no. 7, pp. 3240-3249, 2001.

[153] F. Yao and P. A. Schaffer, "An activity specified by the osteosarcoma line U2OS can substitute functionally for ICP0, a major regulatory protein of herpes simplex virus type 1," Journal of Virology, vol. 69, no. 10, pp. 6249-6258, 1995.
[154] D. Cuchet, R. Ferrera, P. Lomonte, and A. L. Epstein, "Characterization of antiproliferative and cytotoxic properties of the HSV-1 immediate-early ICPo protein," Journal of Gene Medicine, vol. 7, no. 9, pp. 1187-1199, 2005.

[155] R. D. Everett, W. C. Earnshaw, J. Findlay, and P. Lomonte, "Specific destruction of kinetochore protein CENP-C and disruption of cell division by herpes simplex virus immediate-early protein Vmw110," EMBO Journal, vol. 18, no. 6, pp. 1526-1538, 1999.

[156] W. E. Hobbs II and N. A. DeLuca, "Perturbation of cell cycle progression and cellular gene expression as a function of herpes simplex virus ICP0," Journal of Virology, vol. 73, no. 10, pp. 82458255, 1999.

[157] W. J. Bowers, D. F. Howard, A. I. Brooks, M. W. Halterman, and H. J. Federoff, "Expression of vhs and VP16 during HSV-1 helper virus-free amplicon packaging enhances titers," Gene Therapy, vol. 8, no. 2, pp. 111-120, 2001.

[158] K. Igarashi, R. Fawl, R. J. Roller, and B. Roizman, “Construction and properties of a recombinant herpes simplex virus 1 lacking both S-component origins of DNA synthesis," Journal of Virology, vol. 67, no. 4, pp. 2123-2132, 1993.

[159] H. Berthomme, S. Fournel, and A. L. Epstein, "Increased transcomplementation properties of plasmids carrying HSV-1 origin of replication and packaging signals," Virology, vol. 216, no. 2, pp. 437-443, 1996. 

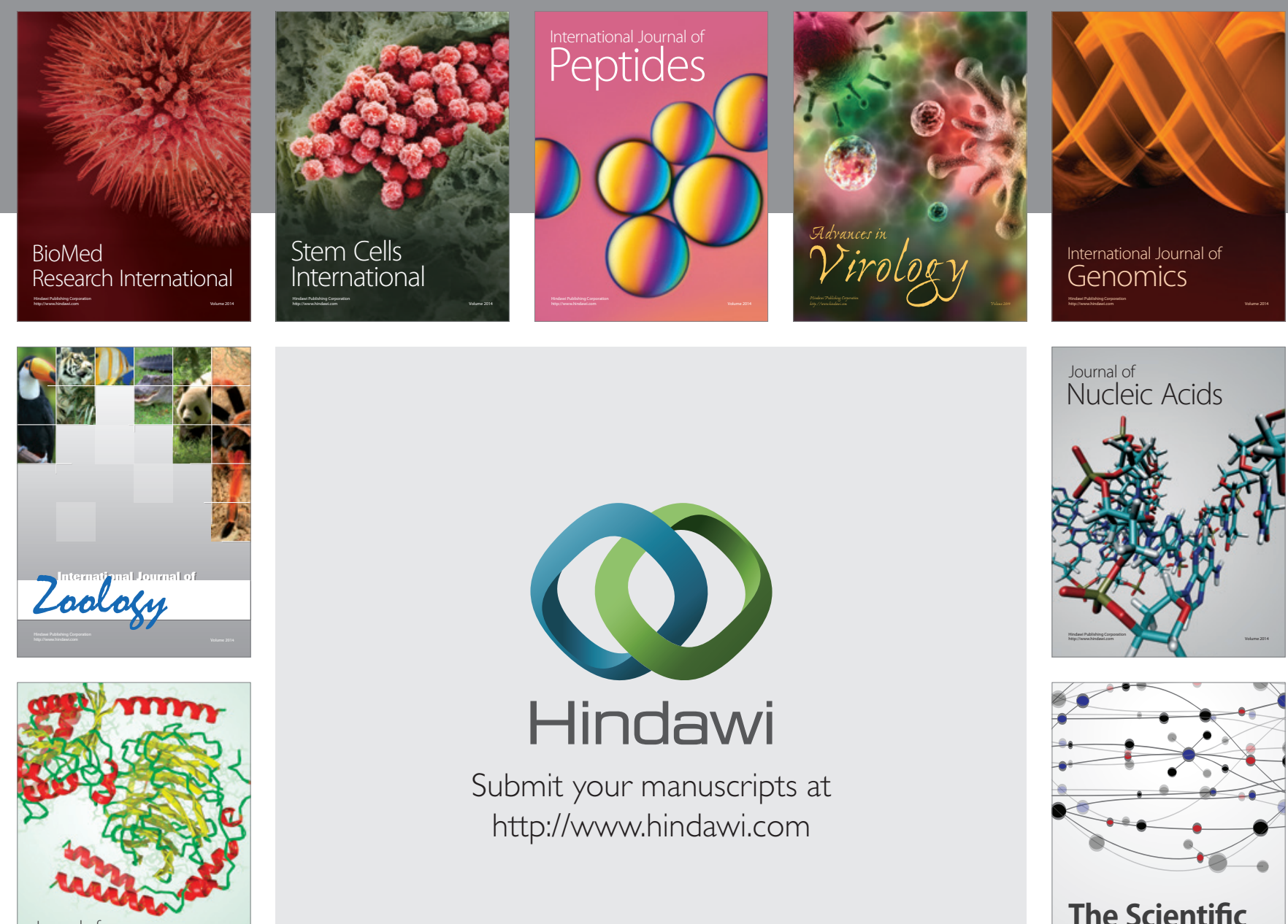

Submit your manuscripts at

http://www.hindawi.com

Journal of
Signal Transduction
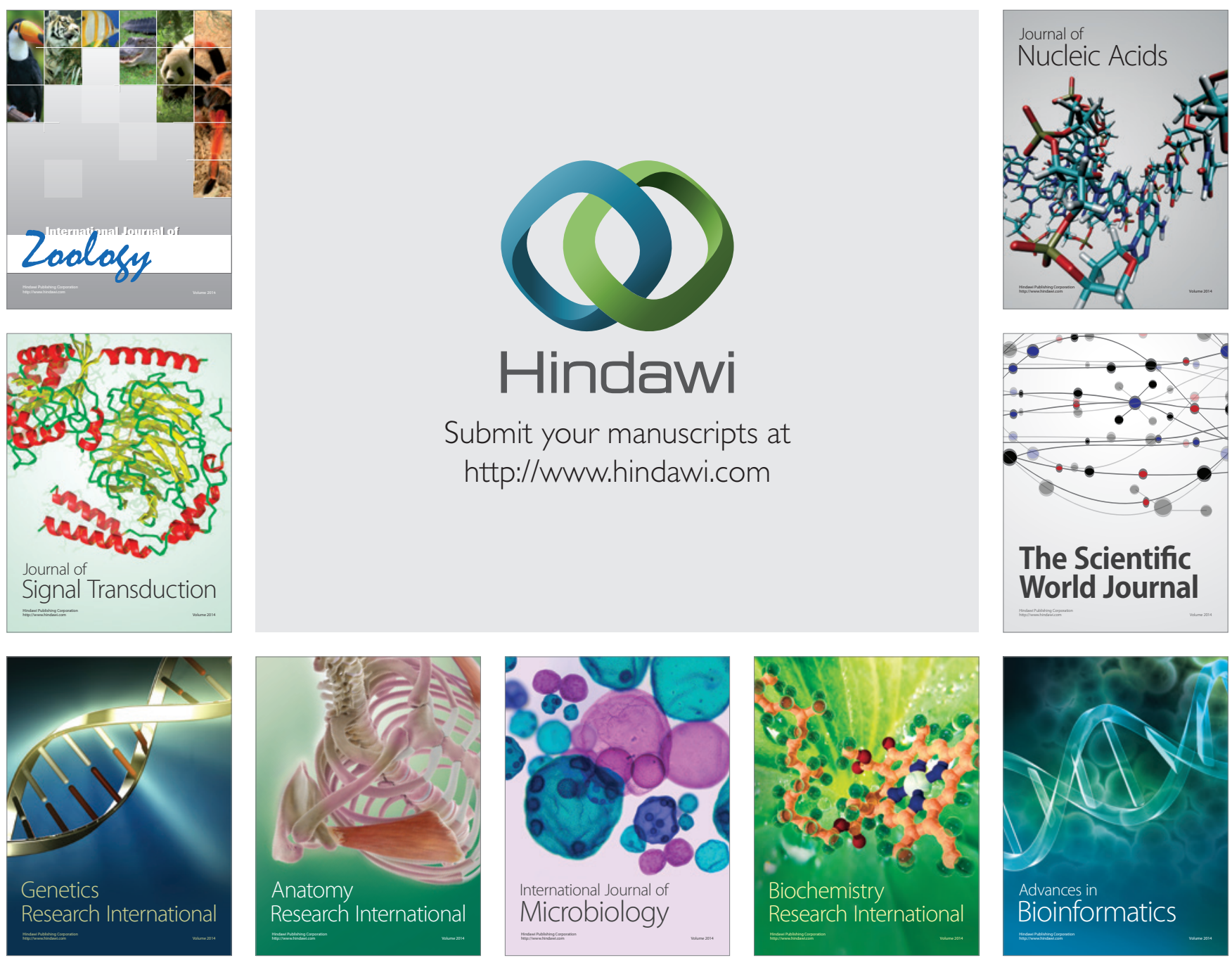

The Scientific World Journal
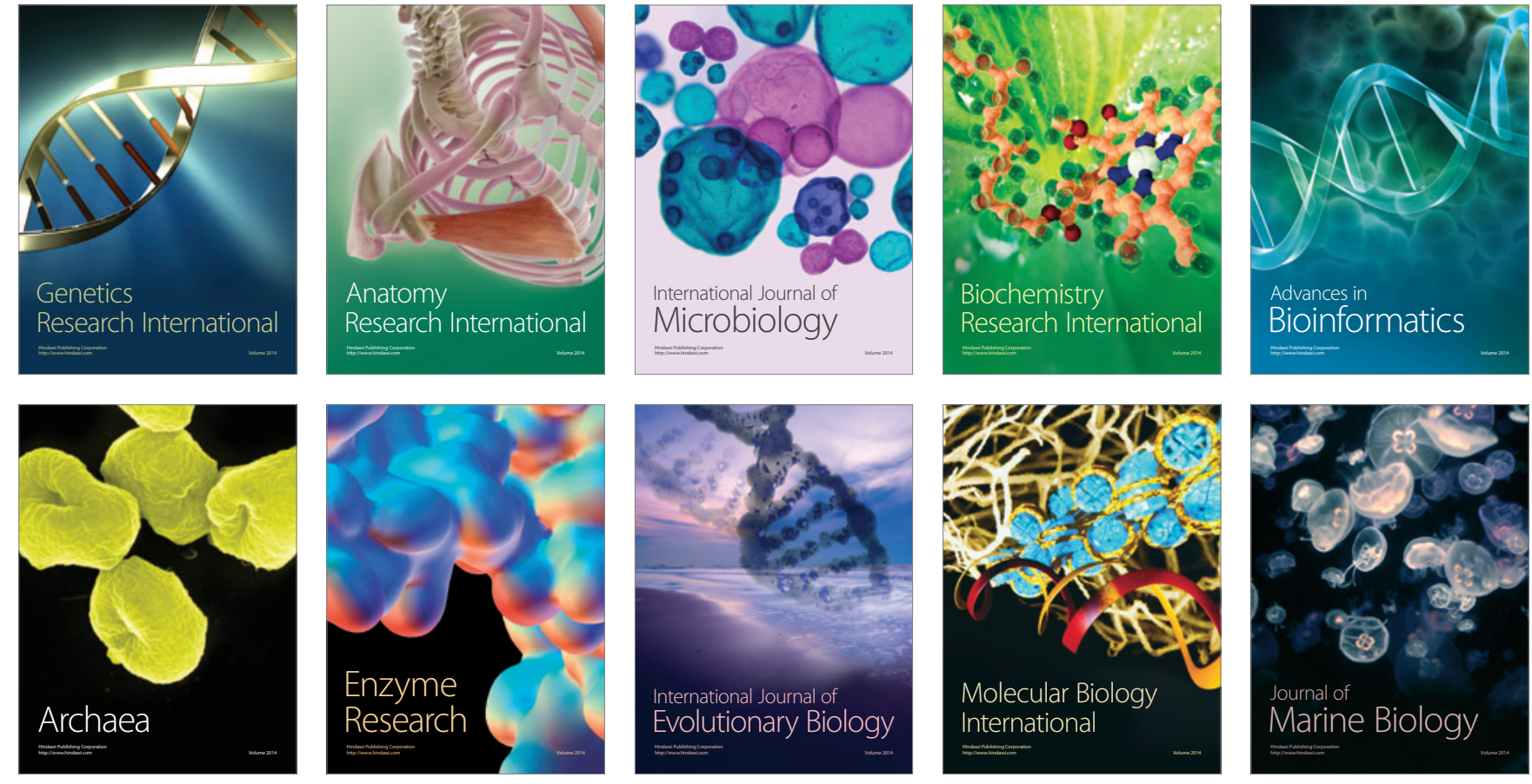